\title{
Balkanologie
}

Balkanologie Revue d'études pluridisciplinaires

Vol. IX, n 1-2 | 2005

Volume IX Numéro 1-2

\section{Les Balkans vus depuis la Turquie : état des lieux des dernières publications}

Reading the Balkans in Turkey: inventory of the latest publications

\section{Sylvie Gangloff}

\section{(2) OpenEdition}

12 Journals

Édition électronique

URL : https://journals.openedition.org/balkanologie/603

DOI : 10.4000/balkanologie.603

ISSN : 1965-0582

Éditeur

Association française d'études sur les Balkans (Afebalk)

Édition imprimée

Date de publication : 1 décembre 2005

ISSN : 1279-7952

Référence électronique

Sylvie Gangloff, "Les Balkans vus depuis la Turquie : état des lieux des dernières publications », Balkanologie [En ligne], Vol. IX, n 1-2 | 2005, mis en ligne le 14 janvier 2010, consulté le 28 juin 2022. URL : http://journals.openedition.org/balkanologie/603; DOI : https://doi.org/10.4000/balkanologie. 603

(c) Tous droits réservés 


\section{ÉTAT DES LIEUX DE LA RECHERCHE}

\section{LES PUBLICATIONS SUR LES BALKANS DANS LES BALKANS}

Cette nouvelle rubrique est destinée à offrir aux lecteurs une présentation des publications sur les Balkans dans les Balkans. Elle offrira, espérons-nous, de nouveaux matériaux aux chercheurs, leur présentera les publications sur leurs centres d'intérêt mais dans des langues qui ne leur sont pas forcément accessibles et donnera un aperçu de la variété (ou non) des thématiques traitées. Note de la rédaction 


\title{
LES BALKANS VUS DEPUIS LA TUROUIE : ÉTAT DES LIEUX DES PUBLICATIONS DEPUIS 1990
}

\author{
Sylvie Gangloff*
}

Le monde de l'édition en Turquie est extrêmement foisonnant. Les coûts relativement modestes d'impression justifient et expliquent cette production très importante en simples termes quantitatifs. Mais si les coûts de production restent modestes, la diffusion est, elle, plus délicate à assurer. En conséquence, de très nombreux ouvrages n'apparaissent que ça et là et, surtout, ils disparaissent aussi vite qu'ils apparaissent. Parfois tirés à 3000,2000 voire 1000 ou 500 exemplaires, la plupart des ouvrages ne restent que quelques semaines en rayon, cédant rapidement la place à de nouvelles parutions.

Dans l'ensemble, la production sur les Balkans occupe une place relativement marginale. Ce sont les questions de politique intérieure (questions sociales, économiques ou purement politiques, et les minorités, juive, alévie, kurde ou autres) qui occupent les plus larges espaces sur les étalages. Dans le domaine international, l'Union européenne accapare les esprits, les recherches et les publications. Il n'y a notamment pas ou peu d'ouvrages sur l'histoire générale des Balkans ; d'où le recours aux traductions. Il s'agit essentiellement d'ouvrages de références sur les Balkans : Barbara Jelavic, Georges Castellan, Maria Todorova, etc. Ces traductions restent finalement d'un coût modeste et comblent des manques notamment sur de sérieuses histoires générales des Balkans ${ }^{1}$. Les conflits yougoslaves ont cependant naturellement motivé un in-

\footnotetext{
- Chercheur associée au Laboratoire d'Etudes turques et ottomanes (UMR 8032). Mail : sylvie.gangloff@afebalk.org

${ }^{1}$ Les traductions ne sont pas prises en compte dans cet état des lieux, de même que les articles parus dans des revues scientifiques.
} 
térêt marqué. On trouve donc de nombreux ouvrages sur les conflits en BosnieHerzégovine ou au Kosovo dans cette recension.

L'Empire ottoman fait l'objet d'une attention toute naturelle mais le sort des terres balkaniques de cet empire est essentiellement traité dans des chapitres d'ouvrages plus généraux. Pour les ouvrages exclusivement consacrés aux Balkans à l'époque ottomane, c'est la thématique migratoire qui domine. Très couverte dans le monde éditorial, les migrations des Balkans vers la Turquie font l'objet de publications à caractère très divers allant de la publication de documents d'archives aux récits plus politiquement engagés (sur le sort des Turcs des Balkans) ou aux mémoires ou témoignages personnels. Ces publications présentent bien sûr des intérêts contrastés parmi lesquels il faut souligner les publications de thèses, souvent de qualité, et les nombreuses publications de documents d'archives (commentés ou non, souvent avec leur traduction en turc). Enfin, des travaux plus anciens font l'objet de traduction en turc et publication ou re-publication, notamment des mémoires ou témoignages de divers protagonistes de l'époque (intellectuels ou fonctionnaires ottomans).

Pour des raisons évidentes de place, seule la période post-199o a été prise en compte ici. Il semble toutefois interessant de noter que deux thématiques ont dominé les publications sur les Balkans dans les années 1980:

- Les relations avec la Grèce et la situation de la minorité turque de Thrace : ces publications sont de tonalité très diverse allant de la synthèse des relations - et controverses - gréco-turques à la publication de documents d'archives $^{2}$.

- Et, surtout après 1985, la situation de la minorité turque de Bulgarie. Nombreux ont notamment été les ouvrages publiés sous l'égide d'organismes officiels. Quelques exemples sont ici mentionnés à titre d'illustration (1 à 8)3.

De fait, les publications sur les Balkans sont largement dominées par des études sur les minorités turques dans les Balkans, leur folklore et leur littérature. C'est le cas dans le monde éditorial mais aussi dans la recherche (et un inventaire des articles publiés dans les revues en Turquie donnerait le même profil). Il faut noter, parmi les auteurs de ces études, une présence notable de Turcs d'origine balkanique : parce qu'ils s'intéressent à la région mais aussi parce qu'ils parlent une ou plusieurs langues balkaniques. On les retrouve, bien sûr, dans les publications associatives, mais pas uniquement ; ils sont assez présents dans le monde de la recherche et, pour certains, sont des " chercheurs émigrés ".

\footnotetext{
2 La question chypriote n'a pas été couverte par cet état des lieux.

3 Les chiffres entre parenthèses renvaient à la liste des publications ci-après.
} 
Parmi les fondations officielles, la Fondation d'histoire turque (Türk Tarih Kurumu - TTK - 〈http://turk.ttk.gov.tr 〉) présente un catalogue de publications très fourni. Cette fondation officielle, créée dans les années 1930, s'est occupée dans un premier temps de codifier l'histoire officielle de la Turquie républicaine (et kémaliste). Ses études sont souvent assez sérieuses mais quelque peu orientées, plus ou moins selon les cas. Un premier thème de publication du TTK est le sort des Turcs de Bulgarie. Elle avait déjà publié sur cette question dans les années 1980 et on retrouve cette thématique, bien que moins présente, après 1991 (9-12, 24). La thématique migratoire fait également l'objet de sérieuses analyses (13-14). La TTK a aussi publié des documents d'archives (21-25) et notamment les volumineuses compilations de documents de Bilâl Șimșir sur les migrations des Balkans ou les Turcs de Bulgarie (23-25).

L'alter ego de la fondation d'histoire, mais cette fois-ci sur les langues, la Fondation de la langue turque, Türk Dil Kurumu (〈www.tdk.gov.tr/〉), a peu publié sur les dialectes turcs des Balkans (26-28). Son impressionnante collection est surtout consacrée aux langues d'Asie centrale, du Caucase ou du Moyen-Orient.

Tout comme le TTK et le TDK, le Centre de recherche Atatürk (Atatürk Araștırma Merkezi) fonctionne sous l'égide du Atatürk Kültür, Dil, ve Tarih Yüksek Kurumu, qui coordonne, depuis 1982, les activités de ces diverses fondations ou centres. L'Atatürk Arașttrma Merkezi organise des conférences et édite des ouvrages essentiellement sur des questions relatives aux premières années de la république de Turquie et sur son fondateur (pour les Balkans 29-32).

La maison d'édition du ministère de la Culture, T.C. Kültür Bakanliğı (<http://www.kultur.gov.tr/〉), met l'accent sur les Turcs de Bulgarie, leur éducation ou leur littérature (33-36), mais elle a aussi publié plusieurs anthologies de poésies, de littérature turques ou des chants populaires turcs dans les Balkans (37-42), des présentations des monuments turcs-ottomans dans les Balkans (43-44) et une étude sur les Turcs de la Dobroudja (45). La présence turque dans les Balkans ou l'héritage culturel ottoman sont, de fait, des thématiques que l'on retrouve - en filigrane ou plus directement traités - dans beaucoup de publications.

Depuis 1992, la Direction des Archives nationales (T.C. Bașbakanlık Devlet Arșivleri Genel Müdürlügü) a signé des accords de coopération dans le domaine des archives avec la plupart des pays balkaniques. Elle a, en conséquence, publié plusieurs catalogues de manuscrits conservés dans ses archives ou des catalogues d'autres sources archivées dans des bibliothèques dans les Balkans (48-54).

Enfin, le Stratejik Arașturma ve Etüdler Milli Komitesi (SAEMK) a été créé par le Haut Conseil de l'Enseignement (Yükseköğretim Kurulu) en 1997 avec pour objectif de produire des recherches sur les relations gréco-turques (58-68). En 2001, le SAEMK (〈www.saemk.org〉) a étendu ses domaines de recherches aux Balkans, au Moyen-Orient et au Caucase. 
L'Institut de recherche sur la culture turque (Türk Kültürünü Araștırma Enstitüsü - TKAE) a été fondé en 1961. C'est un institut non officiel mais qui bénéficie du soutien de l'État. Cet institut a beaucoup publié sur la synthèse turco-islamique et, plus récemment, sur la question arménienne. Le TKAE s'est intéressé aux Balkans dans les années 1980 (entre autres, sur les Turcs de Bulgarie). Son intérêt pour la région s'est atténué dans les années 1990 (69-71) au profit d'autres zones ou thèmes politiques4.

La Fondation de recherche sur les Turcs dans le monde (Türk Dünaysi Araștirmalan Vakfi - TDAV - 〈http://www.turan.org/〉) est une fondation non officielle qui s'intéresse aux "Turcs de l'extérieur ». Ces avocats et mécènes de la " turcité " dans le monde dirigent leur intérêt essentiellement vers l'Asie centrale et le Caucase et ont peu publié sur les Balkans - essentiellement sur les minorités turques ou la présence turque dans la région (sur les Turcs de Macédoine ou les "Turcs pomaks ", 72-74)-quelques traductions également non listées ici. La TDAV publie, également, les revues Türk Dünyası Araștrmalan et Türk Dünyası Tarih Dergisi qui consacrent régulièrement des articles aux minorités turques des Balkans. Il faut noter, par ailleurs, que les publications, exclusivement en turc, de la maison d'édition Balkan Aydmları Yazarlan Yaymlan (BAY), localisée à Prizren, sont largement diffusées en Turquie (75-80).

Le catalogue du Centre de Recherche sur l'Histoire, l'Art et la Culture Islamique, Islam Tarih, Sanat ve Kültür Araștırma Merkezi (IRCICA - <http://ircica.org $>$ ), un organisme financé par l'Organisation de la Conférence Islamique, est essentiellement consacré au monde arabe, mais IRCICA a publié quelques ouvrages sur les Balkans, notamment sur le patrimoine ottoman dans les Balkans $(81-84)^{5}$. La Fondation d'études sur la culture et l'histoire islamique (İslam Tarih, Sanat ve Kültürünü Araștırma Vakfi - ISAR) a également peu publié sur les Balkans (85-87).

Parmi les fondations non officielles, la très sérieuse Fondation d'histoire (Tarih Vakfi) a publié de nombreuses traductions sur les Balkans mais peu de travaux originaux (88-89).

Deux centres de recherches en sciences politiques proposent des collections ou revues sur les Balkans. La Fondation pour les études moyen-orientales et balkaniques, Orta Doğu ve Balkan Incelemeleri Vakfı (OBIV) ou Fondation for Middle East and Balkan Studies, a publié deux volumineux ouvrages sur les Balkans (90-91) et, surtout, elle publie une revue annuelle en anglais sur les Balkans, Turkish Review of Balkan Studies (92). Le Centre de recherches straté-

4 Le Türk Kültürünü Araştırma Enstitüsü publie également, depuis 1964, deux revues : Türk Kültürünü Arastirmalan et Cultura Turcica.

${ }^{5}$ Ne sont pas mentionnés ici les pré-rapports et rapports (publiés) sur la reconstruction du pont de Mostar, en partie financée par IRCICA. 
giques sur l'Eurasie, Avrasya Stratejik Araștırmalar Merkezi (ASAM), a été créé en 1999 autour de l'équipe de la revue Avrasya Dosyası (Dossier Eurasien, trimestriel, depuis 1994). ASAM dispose d'un catalogue et de fonds assez étendus. Ce centre de recherche publie diverses collections par zone géographique (séries sur l'Asie centrale, le Caucase, Russie-Ukraine, etc.), des périodiques (le mensuel Stratejik Analis consacre toujours des articles aux Balkans) et des working papers. La collection sur les Balkans (Balkan Arașturmaları Dizisi) offre sept ouvrages (individuels ou collectifs) (93-100). Ces deux centres de recherche (OBIV et ASAM) sont dirigés et animés par des diplomates (ambassadeurs à la retraite), des militaires à la retraite, des journalistes et des chercheurs-enseignants, un mariage assez classique dans le monde de la recherche et de l'édition en Turquie.

L'armée publie d'ailleurs également des analyses géostratégiques via l'Académie militaire (Harp Akademileri Komutanlığı) ou le bureau du chef d'état major (Genelkurmay bașkanliği) (103-108).

Les maisons d'éditions universitaires ont essentiellement publié des actes de colloques (souvent les textes bruts des communications - donc des articles assez courts). Là encore le thème des minorités turques dans les Balkans domine (109-116). Ces publications ne sont pas toujours très bien diffusées.

Sur les questions économiques, la Chambre de commerce d'Istanbul (Istanbul Ticaret Odasi) offre des études ponctuelles et assez détaillées sur les relations économiques de la Turquie avec certains pays des Balkans (117-122) et la fondation d'études économiques, Íktisadl Araștırmalar Vakfi (Istanbul), a publié les actes des conférences et panels organisés par le vakff: pour les Balkans, publications sur les relations économiques entre la Turquie et la Bulgarie, la Turquie et la Roumanie (123-124). Ces publications ne sont pas, ou peu, distribués dans le réseau des librairies.

Les associations de Turcs originaires des Balkans publient des actes de colloques sur la présence turque dans les Balkans et divers ouvrages sur des questions historiques ou culturelles (126-133). Elles publient également, souvent de façon épisodique, des revues associatives. Certaines revues se distinguent toutefois par leur durée de vie et/ou leur diffusion plus massive. Ne sont considérées ici que les revues toujours (ou nouvellement) diffusées en 2004 : Batı Trakya'nin Sesi (134), Balkan Türk Kültürü (135) et Rumeli Kültürü (136). Ces revues sont essentiellement distribuées dans le réseau associatif et dans quelques bibliothèques.

Hormis ces fondations, associations ou centres de recherche, plus de 500 maisons d'édition se disputent les étalages des libraires en Turquie. Ces maisons d'édition - d'envergure très variée - ont pour certaines édité travaux, recueils ou autres opuscules sur les Balkans. Plusieurs thématiques ou approches se dégagent de cette production. 
Le premier objet d'intérêt est fort logiquement celui des conflits dans les Balkans. De très nombreux ouvrages (une vingtaine recensés ici), plus ou moins sérieux, plus ou moins engagés, ont été publiés, les uns retraçant les conflits en Bosnie ou au Kosovo, les autres présentant les fondements des nationalismes dans la région ou les diplomaties internationales depuis 1992 (137157).

Les frontières entre monde académique, monde politique ou diplomatique et journalisme ne sont, par ailleurs, pas si cloisonnées et, tout comme les diplomates produisent divers travaux académiques, ils sont parfois éditorialistes dans la presse et, à l'inverse, les éditorialistes/journalistes produisent des travaux ou recherches sur les questions d'actualité. Cette mixité des profils des auteurs s'exprime dans la composition des équipes des centres de recherche, tout comme dans le monde de l'édition. Les conflits et les tensions ethniques dans les Balkans ont soulevé un grand intérêt dans la presse et de nombreux journalistes/editorialistes ont alors entrepris d'effectuer des voyages d'étude dans la région. Ce genre littéraire, entre le récit de voyage, le témoignage et l'analyse politique, est assez prisé en Turquie. Il remplit d'ailleurs assez bien la vocation, ouvertement exprimée par les auteurs, de diffusion d'une information accessible à un large public. Ces auteurs se penchent plus particulièrement sur la situation des Turcs de la région, non seulement parce qu'elle les interpelle, mais aussi parce qu'ils trouvent en ces Turcs des interlocuteurs durant leurs voyages (158-164).

Divers travaux et études historiques sur la région, thèses - souvent de bonne tenues - ou documents d'archives, ont fait l'objet de publications : sur la question macédonienne, l'Albanie, la Serbie ou la Bulgarie sous administration ottomane, les migrations des Balkans vers la Turquie, etc. (165-175). La correspondance, le journal ou les mémoires de divers acteurs de l'époque ottomane ou de périodes plus récentes été également été édités ou réédités (176182). La présence turque dans les Balkans, l'héritage ottoman dans les Balkans et les migrations des Turcs suscitent toujours intérêt et travaux. On retrouve ici des thématiques déjà mentionnées (la poésie turque, l'architecture ottomane... 183-199).

Enfin, les relations entre la Grèce et la Turquie motivent toujours de très nombreuses publications, là encore plus ou moins politiquement engagées et objectives (200-216), auxquelles il faut rajouter, entre autres, les publications du SAEMK présentées plus haut. 
Nota : Cette recension se veut la plus complète possible mais ne peut en aucun cas prétendre à l'exhaustivité.

Le nom de famille de l'auteur est suivi de son prénom.

1 - Bulgaristan'da Türk varlığ (La présence turque en Bulgarie), Ankara : TTK, VII (87), 1985, 91 p. + cartes.

Publication des actes d'un colloque. Cartes assez précises du peuplement turc en Bulgarie (villages), quatre articles (langue, peuplement, migrations, droits).

2 - Turkish Presence in Bulgaria, Ankara : TTK, VII (87), 1986, 90 p. + cartes.

Version anglaise du précédent (version arabe en 1987).

3 - Ergenç (Leman), Bulgar Yaymlarmda Türkler (Les Turcs dans les publications bulgares), Ankara : TTK, VII (112), 1989, 97 p. + index et documents.

Analyse des discours sur les Turcs dans plusieurs œuvres bulgares du XIX ${ }^{\text {ème }}$ siècle.

4 - Tekin (Talât), Tuna Bulgarlan ve Dilleri (Les Bulgares du Danube et leur langue), Ankara : TDK, $1987,70 \mathrm{p}$.

Brève histoire des proto-Bulgares et des "Bulgares du Danube "; partie importante du livre dédiée à l'étude de la langue des " Bulgares du Danube " étudiée d'après des inscriptions proto-bulgares ${ }^{6}$.

5 - Nimetullah (Hafiz), Bulgaristan'da çağdaș Türk edebiyatı antolojisi (Anthologie de la littérature turque contemporaine en Bulgarie), Ankara : Kültür ve Turizm Bakanlığı, 1987, $390 \mathrm{p}$.

6 - Șimșir (Bilâl), Bulgaristan Türkleri : 1878-1985 (Les Turcs de Bulgarie : 1878-1985), Ankara : Bilgi, 1986, 403 p.

7 - Keskioğlu (Osman), Bulgaristan'da Türkler : tarih ve kültür (Les Turcs en Bulgarie : histoire et culture), Ankara : Kültür ve Turizm Bakanlığı, 1985, 223 p.

8 - Tuğlacı (Pars), Bulgaristan ve Türk bulgar ilișkileri (La Bulgarie et les relations turco-bulgares), Istanbul : Cem, 1984, 558 p.

9 - Acaroğlu (Türker), Bulgarca ve Bulgaristan üzerine yüzylllık Türkçe kaynakça (Les sources en turc depuis un siècle sur la Bulgarie et le bulgare) Ankara : TTK, XII (8), 19977, 202 p. Un catalogue (non commenté) des publications en turc sur la Bulgarie.

10 - Turan (Ömer), The Turkish Minority in Bulgaria, Ankara, TTK, VII (165), 1998, 350 p.

11 - Gözler (Kemal), Les Origines des Pomaks de Lofça d'après les tahrir defters ottomans: 14791579, Ankara : TTK, XIV (26), 2001, 117 p.

6 Talât Tekin a également publié un ouvrage sur la langue des Bulgares de la Volga, Volga Bulgar Kitabeleri ve Volga Bulgarcası (Le bulgare de la Volga et les inscriptions des Bulgares de la Volga), Ankara : TDK, 1988, $91 \mathrm{p}$.

$7 \mathrm{Il}$ a publié une nouvelle bibliographie, beaucoup plus complète, en 1999, au TC Kültür Bak. 
12 - Șentürk (Hüdai), Osmanlı Devleti'nde Bulgar Meselesi (1850-1875) (La question bulgare dans l'Empire ottoman - 1850-1875), Ankara : TTK, VII (143), 1992, $401 \mathrm{p}$.

L'opposition patriarcat / exarchat, l'activisme des Bulgares, de la Russie, panslavisme, etc.

13 - İpek (Nedim), Rumeli'den Anadolu'ya Türk Göçleri (Les migrations turques de Roumélie en Anatolie), Ankara : TTK, XVI (73), 1994, 260 p.

Publication d'une thèse. Couvre la période 1877-189o, essentiellement à partir des archives du Bașbakanlık (correspondance consulaire et rapports des commissions sur les minorités) : motifs de ces migrations, populations concernées, géographie des départs et des lieux d'installation, aspects sanitaires et sociaux. Index très fourni.

14 - Halaçoğu (Ahmet), Balkan Harbi Surasinda Rumeliden Türk Göçleri (Les migrations turques de Roumélie pendant les guerres balkaniques), Ankara : TTK, XVI (72), 1995, 156 p.

15 - Görgül (İsmet), On ylllık harbin kadrosu, 1912-1922: Balkan-Birinci Dünya ve İstiklal Harbi (L'establishment d'une décennie de guerres - 1912-1922 : les guerres balkaniques, mondiale (Première) et d'indépendance), Ankara : TTK, XIV (69), 1993, 359 p.

16- Kosova Zaferi'nin 600. Yldönümü Sempozyumu (Symposium pour le $600^{\text {ème }}$ anniversaire de la victoire du Kosovo), Ankara : TTK, VII (120), 1992, 54 p.

17 - Uzer (Tahsin), Makedonya Eșkiyalık Tarihi ve Son Osmanlı Yönetimi (L'histoire du brigandage en Macédoine et l'administration de la fin de l'époque ottomane), Ankara : TTK, XVI (25), 1999, $393 \mathrm{p}$.

18 - Kodaman (Bayram), 1897 Türk-Yunan Savaşı (Tesalya Tarihi) (La guerre gréco-turque de 1897. Histoire de la Thessalie), Ankara : TTK, XIV (15), 1993, 118 pages de textes, une centaine de pages de documents.

Publication de documents et poèmes. L'auteur a publié la version ottomane et une traduction en turc.

19 - Nusret (Çam), Yunanistan'daki Türk eserleri (Les monuments turcs en Grèce), Ankara : TTK, XXI (8), 2000, $394 \mathrm{p}$.

Catalogue des monuments, présentation et illustrations.

20 - Ocak (Ahmet Yașar), San Saltuk: Popüler İslâm'n Balkanlar'daki Destani Öncüsü (San Saltık le fondateur légendaire de l'islam populaire dans les Balkans), Ankara : TTK, VII (203), 2002, 155 p.

21 - Balkanlar ve İtalya'da şehir ve manastir arșivlerindeki Türkçe Belgeler semineri (16-17 kasim 200o) (Les Balkans et les documents en turc dans les archives des monastères et des villes en Italie - colloque), Ankara : TTK, XXVI (10), 2003. 83 p. Actes d'un colloque

22 - Atatürk ve yabancı Devlet Bașkanları Vol. IV, Romanya-Yunanistan (Atatürk et les chefs d'Etat étrangers, Vol. IV, Roumanie-Grèce), Ankara : TTK, XVI (62-c), 2001, 610 p.

23 - Şimşix (Bilâl), Rumeli'den Türk Göçleri - Belgeler (Les migrations turques des Balkans Documents), Ankara : TTK, 3 volumes, XVI (50), 1989 : Vol. 1 (1877-1878), 819 p. ; Vol. 2 (1879), 832 p.; Vol. $3(1880-1885), 714$ p.

Publication de documents d'archive commentès : correspondance consulaire (anglaise, fran- 
çaise, turque) et présentation des événements de la période. Index très foumi.

24 - Șimșir (Bilâl), The Turks of Bulgaria in International Fora - Documents, Arkara : TTK, 2 volumes, VII (100), 1990. Sources ottomanes, anglaises, françaises.

25 - Șimşir (Bilal), Ege Sorunu, Belgeler (La question égéenne - Documents), 2 volumes, Ankara : TTK, XVI (29.1 et 29.2) 1982, réédité en 1989 : Vol. 1 (1912-1913), Vol. 2 (1913-1914).

26 - Dallı (Hüseyin), Kuzeydoğu Bulgaristan Türk ağzlan üzerine araștırmalar (Recherches sur les dialectes turques en Bulgarie du nord-est), Ankara : TDK, 1991, 201 p.

Étude des dialectes turcs, de la toponymie et des coutumes locales. Un lexique à la fin.

27 - Hasan (Hamdi), Makedonya ve Kosova Türklerince kullanlan Atasözü ve deyimler (Idiomes et proverbes employés par les Turcs de Macédoine et du Kosovo), Ankara : TDK, 1997 . $234 \mathrm{p}$.

28 - Balkan ülkelerinde Türkçe eğitim ve yaym hayatı bilgi șöleni : $20-24$ nisan 1998 - Bildiriler (Réunion scientifique sur la vie éditoriale et l'éducation en turc dans les pays balkaniques : 20-24 avril 1998 - communications), Ankara : TDK, 1999, $420 \mathrm{p}$.

29 - Turan (Mustafa), Yunan Mezalimi (Izmir, Manisa, Denizli, 1919-1923) (La cruauté grecque : Izmir, Manisa, Denizli), Ankara : Atatürk Araștırma Merkezi, 1999, 474 p.

30 - Sarnay (Yusuf), Saydam (Abdullah), Pehlivanll (Hamit), Pontus meselesi ve Yunanistan'm politikast : makaleler (La question pontique et la politique de la Grèce : articles), Ankara, Atatürk Araștırma Merkezi, 1999. 145 p. ; traduit en anglais, The Pontus and the Policy of Greece, Ankara : Atatürk Araştırma Merkezi, 2000, 114 p.

31 - Eski (Mustafa), Kurtuluş Savaşn'da Yunanlar ve Anadolu Rumlart üzerine makaleler (Açksöz Gazetesi), (Articles sur les Grecs et les Rums anatoliens durant la guene d'indépendance - Le journal Açısöz), Ankara : Atatürk Arașturma Merkezi, 1999, 130 p.

32 - Ylldız (Namık Kemal), Türkdoß̧an (Berna), eds., Romanya Köstence Ovidius Üniversitesi Uluslararası Atatürk Romen-Türk Araștırma Merkezi Faaliyetleri ve Panel Bildirileri, (Communications et activités du centre de recherche turco-roumain Atatürk de l'université Ovidius de Constanța), Ankara : Atatürk Araștırma Merkezi, 2001, 255 p.

33 - Yenisoy (Hayriye Süleymanoğu), Bulgaristan Türk Çocuk Edebiyatundan Örnekler (Exemples de la litterature enfantine des Turcs de Bulgarie), Ankara : T.C. Kültür Bakanlığ, "Türk Dünyası Edebiyatı ", 2002, $380 \mathrm{p}$.

34 - Serefli (Alumet \$erif), Bulgaristan'daki Türkler (1879-1989) (Les Turcs en Bulgarie), Ankara : T.C. Kültür Bakanhı̆ı, « Türk Dünyası Edebiyatı ”, 2002, 738 p.

35 - Memişoğu (Hüseyin), Geçmișten Günümüze Bulgaristan'da Türk Eğitim Tarihi (Histoire de l'éducation turque en Bulgarie d'hier à nos jours), Ankara : T.C. Kültür Bakanlığ, "Kültür Eserleri " (361), 2002, 320 p. 
36 - Acaroğlu (Türker), Bulgaristan Türkleri Üzerine Araștımalar (Les recherches sur les Turcs de Bulgarie), Ankara : T.C. Kültür Bakanlığı, " Kültür Eserleri » (251), 1999, 655 p.

Les recherches produites sur les Turcs de Bulgarie ces 60 dernières années présentées par chapitre : histoire, langue, coutumes.

37 - Mercan (Hasan), Can gergefi. Yugoslavya (Kosova) Türk șiiri antolojisi (Anthologie de la poésie turque yougoslave (Kosovo) - 'Can gergefi'), Ankara : T.C. Kültür Bakanlığı, 2000, 117 p.

38 - Mercan (Hasan), Kosova'da maziye karıșanlar : 15 yaș grubu öğrencilere ve gençlere hikayeler (Le passé du Kosovo : histoires pour des jeunes et des étudiants de 15 ans), Ankara : T.C. Kültür Bakanlığı, 2001, 467 p.

39 - Kösoğlu (Nevzat), İsen (Mustafa), Engüllü (Suat), eds., Bașlangıcından günümüze kadar Türkiye dıșndaki Türk edebiyatlan antolojisi (nesir - nazım) : Makedonya Türk Edebiyatı ve Yugoslavya (Kosova) Türk Edebiyatı (Anthologie de la littérature turque à l'extérieur de la Turquie - de ses origines à aujourd'hui (prose - vers) : la littérature turque en Macédoine et en Yougoslavie-Kosovo), Ankara : T.C. Kültür Bakanlığı, 1997, 461 p.

40 - Sağgam (Feyyaz), ed., Batı Trakya / Yunanistan'da çağdaș Türk edebiyatı antolojisi (Anthologie de la littérature turque contemporaine en Grèce / Thrace occidentale), Ankara : T.C. Kültür Bakanlığı, 1990, 262 p.

41 - Recepoğlu (Altay Suroy), Kosova'da Türk kültürü veya Türkçe düșünmek (La culture turque au Kosovo ou penser en turc), Ankara : T.C. Kültür Bakanlığı, 2001, 420 p.

42 - Ülker (Çiğdem), Makedonya Türk öyküsünde kimlik sorunu (La question identitaire dans les chansons populaires turques de Macédoine), Ankara : T.C. Kültür Bakanlığ , 1998, 182 p.

43 - Virmiça (Raif), Kosova'da Osmanlı Mimari Eserleri (Les œuvres architecturales ottomanes au Kosovo), Ankara : T.C. Kültür Bakanlığı, "Osmanlı Eserleri ” (13), 1999, 787 p.

Présentation, photos et croquis.

44 - Virmiça (Raif), Kosova Hamamları (Les hamams du Kosovo), Ankara : T.C. Kültür Bakanlığ, " Sanat Eserleri " (373), 2002, 135 p.

45 - Nacı (Önal Mehmet), Romanya Dobruca Türkleri (Les Turcs de la Dobroudja roumaine), Ankara : T.C. Kültür Bakanlığı, 1998, 333 p.

Ouvrage sur les coutumes des Turcs de la Dobroudja roumaine (la naissance, le mariage et la mort). Cartes, annexes (extraits de Türkü et mani de Roumanie).

46 - Arslan (Çetin H.), Türk akmci beyleri ve Balkanlarm imarma katklari, 1300-1451 (Les chefs d'akïndji et leur participation au développement des Balkans, 1300-1451), Ankara : T.C. Kültür Bakanlığı, 2001, 242 p.

47 - Artun (Erman), Cemal ritueli ve Balkanlardaki varyantlan (Les rituels de "cemal " et leurs variantes dans les Balkans), Ankara : T.C. Kültür Bakanlığı, 1993, 142 p. + illustrations.

48 - Bosna-Hersek. Bibliografisi (Bosnie-Herzégovine. Bibliographie), Ankara : T.C. Bașbakanllk Devlet Arșivleri Genel Müdürlüğü, Dokümantasyon Daire Bașbakanlı̆̆ (16), 2 volumes, 1995, 1299 p. 
Catalogue des documents d'archive du Bașbakanluk sur la Bosnie-Herzégovine (avec les cotes).

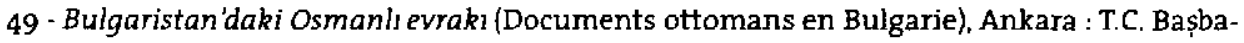
kanlık Devlet Arșivleri Genel Müdürlügü, 1994, 230 p.

Catalogue des documents ottomans dans la bibliothèque nationale bulgare (Kiril : Metodij).

50 - Arșiv belgelerine göre Balkanlar'da ve Anadolu'da yunan mezalimi, (Les cruautés grecques en Anatolie et dans les Balkans selon les archives), Ankara : T.C. Başbakarlık Devlet AIşivleri Genel Müdürlüğ̈̈, Vol. 1, 1995, 685 p.; Vol. 2, 1996, 674 p.; Vol. 3, 1996, 630 p.

51 - Ege Sorunu Bibliyografyası / A Bibliography of the Aegean Question, Ankara : T.C. Bașbakanlık Devlet Arșivleri Genel Müdürlüğü, 1997, 190 p.

52 - Demir (İsmet), ed., Bosna-Hersek ile ilgili arșiv belgeleri (1516-1919) (Documents d'archives à propos de la Bosnie-Herzégovine - 1516-1919), Ankara : T.C. Bașbakanlık Devlet Arșivleri Genel Müdürlügü, Osmanlı Arşivlerí Daire Bașkanlığı, 1992, 685 p.

53 - Binark (İsmet), ed., Bulgaristan'a satulan evrak ve Cumhuriyet dönemi arșiv çalșsmalan (Les documents d'archives vendus à la Bulgarie et les travaux d'archives de l'époque républicaine), Ankara : T.C. Bașbakanlık Devlet Arșivleri Genel Müdürlüğü, 1993, 604 p.

54 - Binark (İsmet), Aktaș (Necati), Kahraman (Seyit Ali), eds., Makedonya'daki Osmanh evrakı (Les documents ottomans en Macédoine), Ankara : T.C. Bașbakanlı Devlet Arşivleri Genel Müdürlüğü, Osmanlı Arşivleri Daire Bașkandığı, 1996, 229 p.

55 - Mercan (Hasan), ed., Balkanlarda çağdaş Türk șiiri antolojisi (Anthologie de la poésie turque contemporaine dans les Balkans), Ankara : T.C. Bașbakanlık Basın-Yayın ve Enformasyon Genel Müdürlügü, 2000, $382 \mathrm{p}$.

56 - Kurnaz (Sefika), Balkan harbinde kadmlarmmzn konuşmalan (Les discours des femmes durant la guerre balkanique), Ankara : T.C. Milli Eğtim Bakanlığ, 1993, 86 p.

57 - Balkanlar'da Kültürel Etkileșim ve Türk mimarisi Uluslararası Sempozyumu bildirileri, 1719 Mays 2000 (Actes du colloque international sur les interactions culturelles dans les Balkans et l'architecture turque), Ankara : Atatürk Kültür Merkezi Bașkanlığ, 2001, 949 p. (2 volumes).

58 - Bostan (İdris), Kurumahmut (Ali), Trablusgarb ve Balkan harplerinde isgal edilen Ege adalan ve ișgal telgrafları (Les îles égennes occupées durant les guerres balkaniques et la guerre de Tripoli et les télégrammes d'occupation), Ankara : SAEMK, 2003, 451 p. Guerres 1912-1913.

59 - Bostan (İdris), Kurumahmut (Ali), Haritalar ve coğrafya eserlerine göre Ege Denizi ve adalan (La mer Egée et ses îles d'après les travaux géographiques et les cartes), Arkara : SAEMK, 2001, $125 \mathrm{p}$.

60 - Adıyeke (Ayșe Nükhet), 'Cemaat-1 İslamiyeler'. Yunanistan smırlari içinde müsülman cemaat örgütlenmeleri 1913-1998 ('Cemaat-1 İslamiyeler'. L'administration des fondations communautaires musulmanes en Grèce, 1913-1998), Ankara : SAEMK, 2001, 119 p. Publié en 2002 en 
version anglaise : "Cemaat-ı Islamiye ". Islamic Community Brotherhood Administrations in Greece (1913-1998).

61 - Aksu (Fuat), Türk-Yunan iliş̧kileri : ilişkilerin yönelimini etkileyen faktörler üzerine bir inceleme (Les relations gréco-turques : Recherches sur les facteurs influençant les orientations de ces relations), Ankara : SAEMK, 2001, 365 p.

62 - Başaran (Sertaç Hami), Kurumahmut (Ali), Ege'de egemenliği devredilmemişadalar (Les îles qui ne sont pas tombées sous domination en Egée), Ankara : SAEMK, 2003, 188 p.

63- Küçük (Cevdet), Ege adalarmmn egemenlik devri tarihçesi (Brève histoire de la période de souveraineté ottomane sur les îles égéennes), Ankara : SAEMK, 2001, 395 p. ; republié en 2002 en anglais : $A$ Sort history of the period of the Ottoman sovereignty of the Agean islands.

64 - Bostan (İdris), Ege adalarínn idarî, malî ve sosyal yapısı (Structure sociale, économique et administrative des îles égéennes), Ankara : SAEMK, 2003, $183 \mathrm{p}$.

65 - Küçük (Cevdet), ed., Türk hakimiyetinde Ege adalarínın yönetimi (Administration des îles égéennes sous gouvernement turc), Ankara : SAEMK, 2002.

66 - Ayman (Gülden), Güç, tehdit ve ittifaklar. Neo-realist bir perspektiften soğuk savaş sonrası Yunan dus politikası (Pouvoir, menaces et alliances. La politique extérieure de la Grèce après la guerre froide dans une perspective néo-réaliste), Ankara : SAEMK, 2001.

67 - Oran (Baskan), Yunanistan'm Lozan ihlalleri (Les violations de Lausanne par la Grëce), Ankara : SAEMK, 1995, 108 p. Republié en 1999 et de nouveau en 2002 en anglais : Greek Violations of the Lausanne Treaty.

68 - Hatipoglu (Murat), Yunanistan'da Etnik Gruplar ve azmllklar (Les groupes ethniques et les minorités en Grèce), Ankara : SAEMK, 1999, $183 \mathrm{p}$.

Les minorités turque, slavo-macédonienne, valaque, albanaise, juive. Survol historique depuis l'indépendance de la Grèce puis situation présente détaillée, les discriminations et violations des droits de l'homme. Archives turques, documents du Helsinki Committee.

69 - Memişoğlu (Hüseyin), Bulgaristan'da Türk Kültürü (La culture turque en Bulgarie), Ankara : Türk Kültürü Araştırmalan Enstitüsü (145), 1995, 211 p.

70 - Baștav (Șerif), Osmanl Türk-Macar Münasebetlerinde ilk devir (Première période des relations ottomano-hongroises), Ankara : Türk Kültürü Arașturmalan Enstitüsü, 1991, 188 p.

71 - Gülsoy (Ufuk), 1828-ı829 Osmanlt-Rus savașinda Rumeli'den Rusya'ya göçürülen reaya (Les Reayas qui ont migré de Roumélie vers la Russie durant la guerre russo-ottomane de 1828-1829), Ankara : Türk Kültürü Araștırmalan Enstitüsü, 1993, 160 p.

72 - Şahin (İhan), Öke (Kemal), Zaim (Kazım), Karaman (Lütfullah), Bosna-Hersek (La Bosnie-Herzégovine), Istanbul : TDAV, 1992, $244 \mathrm{P}$.

73 - Kalafat (Yașar), Makedonya Türkleri (Les Turcs de Macédoine), Istanbul : TDAV, 1994, 54 P. 
Petit ouvrage sur les croyances populaires des Turcs et des Torbeș de Macédoine, sous forme de témoignage.

74 - Memișoğu (Hüseyin), Balkanlarda Pomak Türkleri (Les Turcs pomaks dans les Balkans), Istanbul : TDAV, 1999, $112 \mathrm{p}$.

Histoire des "Turcs pomaks ", dialecte, vie socio-économique, lutte contre les Bulgares et les Russes durant la guerre de $1877-1878$, la politique d'assimilation de la Grèce, les migrations ${ }^{8}$.

75 - Recepoğu (Altay Suroy), Prizren çeșmeleri, șiirler, bilgiler, belgeler (Les fontaines de Prizren, poèmes, connaissances, documents), Prizren : BAY, "Araștırma-inceleme " (2), 2003, $190 \mathrm{p}$.

76 - Baymak (Osman), ed., Kosova-Prizren'de Osmanl eserleri : araștırma-inceleme (Les œuvres ottomanes à Prizren-Kosovo, recherches-travaux), Prizren : BAY, 2001, 386 p.

77 - Recepoğlu (Altay Suroy), Canlı kitabeyiz - Kosova'da șiirler (Les poésies au Kosovo - nous sommes une épitaphe vivante), Prizren : BAY, "Araștırma-inceleme " (3), 2004.

78 - Recepoğlu (Altay Suroy), Kosova'da Türkçe veya kimlik mücadelesi (La langue turque au Kosovo ou la lutte identitaire), Prizren : BAY, " Araștırma-inceleme " (4), 2004.

79 - Recepoğu (Altay Suroy), Belgrat Camileri (Les mosquées de Belgrade), Prizren : BAY, "Araștırma-inceleme " (5), 2004, 118 p.

80 - Güler (Hüseyin Rasim), Bulgaristan Türkleri'nin Rumeli Türküleri (Les chansons populaires balkaniques des Turcs de Bulgarie), Prizren : BAY, "Araștırma-inceleme " (6), 2004, $191 \mathrm{p}$.

Les paroles de plus de 300 chansons populaires de Bulgarie.

81 - Balkanlar'da İslâm Medeniyeti Milletlerarası Sempozyumu Tebliğleri, Sofya, Nisan 21-23, 2000 (Actes du symposium international sur la civilisation islamique dans les Balkans), Istanbul : IRCICA, 2002, $447 \mathrm{p}$.

Ce premier volume rassemble les contributions des participants turcs.

82 - Proceedings of the International Symposium on Islamic Civilisation in the Balkans, Sofia, April 21-23, 2000, Istanbul : IRCICA, 2002, $301 \mathrm{p}$.

Ce deuxième volume rassemble les articles en anglais et en bulgare (128 pages sur 301 sont en anglais).

83 - Handzic (Adem), Population of Bosnia in the Ottoman Period. A Historical Overview, Istanbul : IRCICA, 1994, $42 \mathrm{p}$.

84 - Handžić (Adem), A Survey of Islamic Cultural Monuments until the end of the $19^{\text {th }}$ Century in Bosnia, Istanbul : IRCICA, 1996, 118 p. (index et photographies).

Inventaire des vakf, mosquées et écoles coraniques d'une cinquantaine de villes et villages en Bosnie (à l'exception de Sarajevo qui n'a pas été couvert). Inclus un glossaire, un index et des photographies.

\footnotetext{
${ }^{8}$ L'auteur avait déjà publié un petit ouvrage (68p.) sur ce sujet en 1991 aux éditions Șafak (Ankara).
} 
85 - İhsanoğ̀ (Ekmeleddin), Bulgaristan'da Türk-Islam egitim ve kültür müesseseleri ve Medresetü'n-Nüvvab (L'éducation turco-islamique, les institutions culturelles et le " Medresetü'n-Nüvvab " en Bulgarie), Istanbul : ISAR, 1993, 111 p.

86 - Nemlioğu (Candan), Bosna-Hersek Foca'da yok edilen Türk-islam kültür eserleri (Les monuments culturels turco-islamiques qui ont eté détruits à Foça en Bosnie-Herzégovire), Istanbul : İSAR, 1996, $116 \mathrm{p}$.

87 - Bıçakçı (İsmail), Yunanistan'da Türk mimari eserleri (Les œuvres architecturales turques en Grèce), Istanbul : ISAR, 2003, 435 P.

88 - Babuna (Aydın), Geçmișten günümüze Boşnaklar (Les Bosniaques d'hier à aujourd'hui), Istanbul : Tarih Vakf1, 2000, $235 \mathrm{p}$.

89 - Millas (Herkül), Daha iyi Türk Yunan ilișkileri için yap yapma klavuzu (Guide de ce qu'il faut faire et ne pas faire pour améliorer les relations gréco-turques), Istanbul : Tarih Vakfi, 2002, $71 \mathrm{p}$.

Quelques réflexions sur les perceptions réciproques des Grecs et des Turcs.

90 - Balkanlar (Les Balkans), Istanbul : Eren / OBiv, 1993, 299 p.

Ouvrage collectif qui couvre les Balkans de l'époque ottomane à nos jours en se voulant assez exhaustif : l'ensemble de la période est couverte et, sur le contemporain, divers aspects sont abordés : guerres yougoslaves, relations gréco-turques ou migrations.

91 - Dağılan Yugoslavya ve Bosna-Hersek Sorunu : Olaylar-Belgeler, 19go-19g6 (La désintégration de la Yougoslavie et la question bosniaque. Faits et documents, 1990-1996), préparé par İsmail Soysal et Șule Kut, Istanbul : İSíS / OBIV, 1997, $341 \mathrm{p}$.

Chronologie détaillée (sur 150 pages) des événements mois par mois en Bosnie-Herzégovine dans les années 1990-1996; documents.

92 - Turkish Review of Balkan Studies, OBIV, Annuel en anglais, depuis 1993 chez ISIS (Istanbul), puis (2003) chez Bigart (Istanbul).

93 - Karatay (Osman), Hırvat Ulusunun olușumu. Erken ortaçağda Türk-Hırvat ilişkileri (La formation de la nation croate. Les relations turco-croates au début du moyen âge), Ankara : ASAM, « Balkan Araşturmalan Dizisi " (1), 2000, 221 p.

94 - Lütem (Ömer). Türk-Bulgar llișkileri, 1983-1989 (Les relations turco-bulgares, 1983-1989), Vol. 1, 1983-1985, Ankara : ASAM, " Balkan Arașturmalan Dizisi » (2), 2000, 600 p.

Par un ancien ambassadeur. Source : presse turque. Un second volume est annoncé.

95 - Lütem (Ömer), Demirtaș-Coșkun (Birgül), eds., Balkan Diplomasisi (Diplomatie balkanique), Ankara : ASAM, "Balkan Arașturmalan Dizisi " (3), 2001, 311 p.

Ouvrage collectif. Des articles sur la Bosnie-Herzégovine, la politique extérieure de la Croatie, la Grèce et la Macédoine, le nationalisme albanais, etc.

96 - Demirtaş-Coṣkun (Birgül), Bulgaristan'la yeni dönem. Soğuk Savaş Sonrası Ankara-Sofya İişkileri (Nouvelle période avec la Bulgarie. Les relations entre Ankara et Sofia après la Guerre froide), Ankara : ASAM, " Balkan Araștırmalan Dizisi " (4), 2001, 126 p. 
97 - Șimșir (Bilâl), Türkiye-Arnavut ilișkileri, Büyükelçilik anılan (1985-1988) (Les relations turco-albanaises, mémoires d'ambassadeur), Ankara : ASAM, " Balkan Arașturmalan Dizisi " (5), 2001, $510 \mathrm{p}$.

Mémoires d'un ancien ambassadeur. Couvre la période 1985-1988.

98 - Hatipoğu (Murat), ed., Makedonya sorunu : dünden bugüne (La question macédonienne d'hier à aujourd'hui), Ankara : ASAM, " Balkan Arașturmalan Dizisi " (6), 2002, 187 p.

Articles sur la Macédoine à l'époque ottomane, la minorité slavo-macédonienne en Grèce, les Turcs de Macédoine, etc.

99 - Demirtaş-Coṣkun (Birgül), ed., Türkiye-Yunanistan : eski sorunlar, yeni arayışlar (Turquie-Grèce - anciennes questions, nouvelles réflexions), Ankara : ASAM, "Balkan Arașturmalan Dizisi " (7), 2002, 238 p.

100 - Türbedar (Erhan), ed., Balkan Türkleri (Les Turcs balkaniques), Ankara : ASAM, 2003, 350 p.

101 - Kut (Şule), Makedonya ve sorunlan (La Macédoine et ses problèmes), Istanbul : Türkiye Sosyal Ekonomik Siyasal Arașturmalar Vakfi (TÜSES), 1993, 67 p.

102 - Arnavutluk mevzuatı: 1993-1994-1995 (La législation albanaise, 1993-1994-1995), Ankara : Türk İșbirliği-Kalkınma (Tika), 1995, 144 p.

103 - Makedonya (Macédoine), Istanbul : Harp Akademileri Komutanlığı, 1992, 177 p.

104 - Balkanlar'm dünü, bugünü, yarmı (Les Balkans, hier, aujourd'hui, demain), Istanbul : Harp Akademileri Komutanlığ, 1993, 208 p.

105 - Balkanlardaki gelișmeler ve Türkiye'ye etkileri ile Balkanlar-Türkiye otoyol projesi (Les développements dans les Balkans et leur influence sur la Turquie et le projet d'autoroute Balkan-Turquie), Istanbul : Harp Akademileri Komutanlığ, 1999, 191 p.

106 - Osmanl-Rus Harbi (1877-1878) Koleksiyonu kataloğu (Catalogue de la collection sur la guerre russo-turque, 1877-1878), coordinateurs du projet : Hüseyin Görür, Nasır Yüceer, Ankara : Genelkurmay Bașkanlığı, 4 volumes, 1994-1995 : Vol. 1, 1994, 336 p.; Vol. 2, 1994, 317 p.; Vol. 3, 1995,400 p.; Vol. 4, 1995, 388 p.

Catalogue des archives militaires sur la guerre russo-turque de 1877-78.

107 - Öznal (Erdoğan), Makedonya Yunan değildir (La Macédoine n'est pas grecque), Ankara : Genelkurmay Bașkanlığı, 1993, 81 p.

108 - Türk Silahl Kuvvetleri Tarihi: Balkan Harbi (Histoire des forces militaires turques : la guerre balkanique), Ankara : Genelkurmay Bașkanlığı, 1993.

Comprend également de nombreuses cartes détaillées des opérations militaires.

109 - Tarihte Güney-Doğu Avrupa : Balkanolojinin dünü, bugünü ve sorunlan - South-east Europe in History : The past, the present and problems of Balkanology, Ankara : Ankara Üniversitesi, Dil ve Tarih-Coğrafya Fakültesi, 1999, $141 \mathrm{p}$.

Actes d'un colloque sur les sources, les archives et quelques questions. Articles en turc et en anglais. 
110 - Balkanlar'daki Türk Kültürü'nün Dünü-Bugünü-Yarmı Uluslararası Sempozyum (26-28 Ekim 2001), Bildiri Kitabı (La culture turque dans les Balkans, passé-présent-futur, actes du colloque international, 26-28 octobre 2001\}, Bursa : Uludağ Üniversitesi Rektörlüğü, Uludağ Üniversitesi, 2002, $270 \mathrm{p}$.

111 - Balkan Türkleri Sempozyomu - Tebliğler (Colloque sur les Turcs des Balkans - communications), Kayseri : Erciyes Üniversitesi (34), 1992, 81 p.

112 - Tarih Boyunca Balkanlardan Kafkaslara Türk Dünyası Semineri; 29-31 Mayıs, 1995: bildiriler (Conférence sur le monde turc des Balkans au Caucase au cours de l'histoire-communications), Istanbul : İstanbul Üniversitesi, Edebiyat Fakültesi, 1996, $207 \mathrm{p}$.

113 - Balkanlar'da Türk Mührü (L'empreinte turque dans les Balkans), Istanbul : Istanbul Üniversitesi, Türkiyat Araștırmalan Enstitüsü $\left(\mathrm{n}^{\circ}{ }^{1}\right), 1998,239 \mathrm{p}$.

Actes de deux colloques organisés les $24-29$ septembre 1979 et $20-25$ septembre 1982 , une trentaine de communications publiées.

114 - Ergenç (Leman), Bulgar edebiyat tarihi (Histoire de la littérature bulgare), Ankara : Ankara Üniversitesi Dil Tarih Cografya fakültesi (378), 1996, 103 p.

115 - Arnavutluk Devlet Arşivlen Osmanlı Yazmalan Kataloğu / Katalogu i Dorëshkrimeve Osmane ne Arkivat e Shqiperise / Ottoman Manuscripts Catalog of Albanian State Archives, préparé par Giyasettin Aytaș, Haci Yilmaz, Ankara : Gazi Üniversitesi Türk Kültürü ve Hacı Bektaş Veli Araștırma Merkezi (1), 2001, XLIX+211 p. (en turc, albanais, anglais)

116 - Diş̧̦i (Rian), Sözlük Türkçe-Arnavutça-Ingilizce = Fjalor shqip-turqisht-anglish = Dictionary english-turkish-albanian, Istanbul : Istanbul Üniversitesi İletișim Fakültesi Basımevi ve Film Merkezi, 1994, 520 p.

117 - Romanya - ülke profili, mevzuat, Türk girișimcileri ve Türkiye-Romanya serbest Ticaret anlaşması (La Roumanie - profil du pays, législation, les entreprises turques et l'accord turcoroumain de libre échange), Istanbul : İstanbul Ticaret Odas1, 1997, $154 \mathrm{p}$.

118 - Slovakya - ülke profili ve Türkíye-Slovakya serbest anlaşmast (La Slovaquie - profil du pays et accord turco-slovaque de libre échange), Istanbul : İstanbul Ticaret Odas1, 1998, 176 p.

119 - Bulgaristan - ülke profili, mevzuat ve Türk girişimcileri (La Bulgarie - profil du pays, législation et entreprises turques), Istanbul : İstanbul Ticaret Odas1, 1998, 167 p.

120 - Makedonya - ülke etüdü (La Macédoine - étude du pays), Istanbul : İstanbul Ticaret Odası, 1999, $106 \mathrm{p}$.

121 - Bulgaristan - ülke etüdü ve Türk yatrrmlan (La Bulgarie - étude du pays et investissements turcs), Istanbul : İstanbul Ticaret Odas1, 2003, $80 \mathrm{p}$.

122 - Romanya - ülke etüdü ve Türk yatrrmlan (La Roumanie - Etude du pays et investissements turcs), Istanbul : İstanbul Ticaret Odas1, 2003, 123 p. 
123 - Türkiye-Bulgaristan Ekonomik hişkleri Konferans - Sofya - 1998 (Les relations économiques entre la Turquie et la Bulgarie - Conférence - Sofia, 1998), Istanbul : İktisadı Araştırmalar Vakfi, 1998, $114 \mathrm{p}$.

124 - Türkiye-Romanya Ekonomik ñişkilerinin Geliștirilmesi - Konferans - Bükreş - 1998 (Le đéveloppement des relations économiques entre la Turquie et la Roumanie - conférence, Bucarest, 1998), Istanbul : İktisadı Araştırmalar Vakfi, 1998, 98 p.

125- Çolak (Ömer Faruk), ed., Avrupa Birliğine giriş sürecinde Balkanlarla ilișkiler ve Türkiye ekonomisi (L'économie turque et les relations avec les Balkans dans le processus d'adhésion à l'UE), Ankara : Türkiye Ekonomi Kurumu, 2003, 224 p.

126 - Vatan (Kemal), ed., Makedonya'da Rumeli Türkleri'nin tarihi ve kültürleri panelleri ve konferansi (Conférence et panels sur la culture et l'histoire des Turcs rouméliotes de Macédoine), Izmir : İzmir-Makedonya Göçmenleri Kültür ve Dayanışma Demeği, 1996, 168 p.

127 - Ağanoğu (Yldınm), ed., Türklerin Rumeli'ye çkı̧smm 650, yldönümü (650ème anniversaire de l'arrivée des Turcs dans les Balkans), Istanbul : Rumeli Türkleri Kültür ve Derneği, 2003,346 p.

Actes d'un colloque organisé en $\mathbf{2 0 0 2}$. Articies principalement sur les minorités turques dans les Balkans et les développements socio-économiques dans la région.

128 - Kahramanyol (Mustafa), ed., Makedonyadaki Türk ve Müslüman toplumlarmm dilleri konusunda karşılaștırmalt sözlük : (Türkçe- Arnavutça- Boșnakça- Pomakça) (Dictionnaire comparatif des langues des sociétés musulmane et turque de Macédoine (turc-albanais-bosniaque-pomak), Ankara : T.C. Devlet Bakanlı̆g-TIKA / Bosna-Hersek Dostları Vakfı / Balkan Barıș, Özgürlükler ve Geliștirme Derneği, 2002, $90 \mathrm{p}$.

129 - Aganoğu (Yuldınm), ed., 1896 - Kosova Vilayeti Salnamesi (Almanach du vilayet de Kosovo), Istanbul : Rumeli Türkleri Kültür ve Dayanıșma Demeği, 2003, 382 p.

Situation militaire, économie, commerce, éducation, population, agriculture, structures sociales dans le vilayet de Kosovo (Priștine, Prizren, İpek, Yenipazar et Tașlıca).

130 - Ağanoğu (Yıldınm), ed., Yücel Teșkilatı (II dünya savașın'da Yugoslavya'da bir direniş mücadelesi) (L'organisation 'Yücel' - une lutte de résistance en Yougoslavie durant la Seconde Guerre mondiale), Istanbul : Rumeli Türkleri Kültür ve Dayanıșma Derneği, 2003.

131 - Tusufoğu (Hicran), Osmanl-Macar ilişkileri (Les relations osmano-hongroises), Ankara : Türk-Macar Dostluk Derneği Yayınlan / Sam, 1995, 126 p.

132 - Sag̈lam (Feyyaz), Yunanistan'da (Batı Trakya'da) çağdaș Türk șiiri antolojisi (Anthologie de la poésie turque contemporaine en Grèce - Thrace occidentale), Izmir : Batı Trakya Türkleri Dayanıșma Derneği (BTTDD), 1995 [2002], 246 p. 
133 - Sağlam (Feyyaz), Batı Trakya Türkleri Basm-Yaym Tarihi (Histoire des publications-éditions des Turcs de Thrace occidentale), Izmir, 2002, $240 \mathrm{p}$.

Catalogue des publications des Turcs de Thrace occidentale, en Grèce, en Europe occidentale ou en Turquie publié par la Fédèration européenne des Turcs de Thrace en Allemagne ${ }^{9}$ et republié en Turquie à compte d'auteur.

134 - Batı Trakya'nın Sesi (La voix de la Thrace Occidentale), Istanbul : Batı Trakya Türkleri Dayanıșma Derneği (Association des Turcs de Thrace). Mensuel puis, depuis 1997, bimestriel.

135 - Balkanlarda Türk Kültürü Dergisi (La Revue culturelle des Turcs des Balkans), Bursa : Association Bal-Göç. Trimestriel.

136 - Rumeli Kültürü (La culture balkanique), Istanbul : Rumeli Türkleri Kültür ve Dayanışna Vakfi. Trimestriel, depuis 2002.

137 - Özdoğan (Günay Göksui), Saybașll (Kemâli), eds., Balkans. A Mirror of the New International Order, Istanbul : Eren, 1995, 351 p.

Ouvrage collectif dont les articles couvrent l'ensemble des questions diplomatiques dans les Balkans.

138 - Saybaşılı (Kemâli), ed., Yeni Balkanlar, eski sorunlar (Nouveaux Balkans, anciennes questions), Istanbul : Bağlam, 1997, $311 \mathrm{p}$.

139 - Çalış (\$aban H.), Hayaletbilimi ve hayali kimlikler : Neo-osmanclik, Özal ve Balkanlar (Fantasmagorie et identités imaginées : le néo-ottomanisme, Özal et les Balkans), Konya : Çizgi, 2001, $208 \mathrm{p}$.

140 - Küpeli (Yusuf), Tarihin izinde Balkanlar ve ABD (Les États-Unis et les Balkans dans une perspective historique), Ankara : Öncü, 2000, $222 \mathrm{p}$.

141 - Özgür (Nurcan), Etnik Sorunlarm Çözümünde Etnik Parti, Hak ve Özgürlükler Hareketi, 1989-1995 (Un parti ethnique dans la résolution des questions ethniques. Le Mouvement des Droits et des Libertés - 1989-1995), Istanbul : Der, 1999. 469 p.

Sources turques et bulgares, travail de terrain important.

142 - Akarslan (Mediha), Bosna-Hersek ve Türkiye (La Bosnie-Herzégovine et la Turquie), Istanbul : Ağaç, 1993, 104 p.

Petit ouvrage qui porte essentiellement sur l'histoire de la Bosnie-Herzégovine, de la Yougoslavie et des Balkans.

143 - Tuluç (Doğan), Milliyetçiliğin pençesindeki kartal. Kosova (L'aigle dans les griffes du nationalisme. Le Kosovo) Ankara : Ümit, 1999, 204 p.

Les fondements des nationalismes albanais et serbe, les politiques américaine, européenne et turque dans la région.

9 Bavyera Eyaleti Batı Trakya Türkleri Aile Birlig̈i (Union familiale des Turcs de Thrace occidentale - province de Bavière), Munich. L'auteur a également publié plusieurs autres ouvrages sur la littérature turque de Thrace occidentale à la section de Dusseldorf de l'association, à la section australienne (Melbourne Batı Trakya Türk İslam Dayanışma Derneği) ou au Batı Trakya Araştırma Merkezi (centre de recherche sur la Thrace occidentale) de Munich. 
144 - Karatay (Osman), Bosna-Hersek barș süreci - Dayton Barș antlaşması eki ile (Le processus de paix en Bosnie-Herzégovine - accord de Dayton en annexe), Ankara : Karam, 2002, $184 \mathrm{p}$.

145 - Karatay (Osman), Kosova Kanlı Ova (Kosovo, la plaine ensanglantée), Istanbul : İz, 1998, $173 \mathrm{p}$.

Présentation succincte de l'histoire du Kosovo par étapes historiques.

146 - Selver (Mustafa), Balkanlara Stratejik yakmlassm ve Bosna (La Bosnie et le rapprochement stratégique vers les Balkans), Istanbul : İQ Kültür Sanat, 2003, $224 \mathrm{p}$.

Géographie, population, histoire depuis le Congrès de Berlin jusqu'au accords de Dayton.

147 - Ülger (İrfan Kaya), Yugoslavya Neden Parçalandi : Balkan Drammm Perde Arkası (Pourquoi la Yougoslavie a-t-elle implosé : les coulisses d'une tragédie balkanique), Ankara : Seçkin, 2003, 256 p.

148 - Koca (Mucahit), Bosna kitabi (Le livre bosniaque), Istanbul : Sur, 1999. 64 p.

149 - Hatipoğu (Tahix), Bosna'ya farkhl bakıss : gözlem-yorum-tartșma (Un autre regard sur la Bosnie : observations-interprétation-discussion), Istanbul : Selvi, $140 \mathrm{p}$.

150 - Burhan (Metin), Unaltay (Altay), Bosna-Hersek ve postmodern ortaçağa giriș (La BosnieHerzégovine et l'entrée dans le Moyen-Age postmoderne), Istanbul : Birleșik, 1996, 477 p.

151 - Yahya (Harun), Gizli el Bosna'da: Strplarm arkasindaki anti-islami enternasyonel'in bilinmeyen hikayesi (La main secrète en Bosnie : histoire de l'internationale anti-islamique derrière les Serbes), Istanbul : Vural, 1997, 253 p.

152 - Karatay (Osman), Ba'de Haräbi'l - Bosna (Après la destruction de la Bosnie), Istanbul : İz, $1997,234 \mathrm{p}$.

153 - Gunay (Ertegrul), Bosna yazllart : Bosna için insanllk girişimi (Les écrivains bosniaques : une initiative humaine pour la Bosnie), Istanbul : AD, 1997, $222 \mathrm{p}$.

154 - Alkan (Necmettin), Dağlan Yugoslavya mozaiğinde Bosna (La Bosnie dans la mosaïque yougoslave éclatée), Istanbul : Beyan, 1995, $240 \mathrm{p}$.

155 - Erduran (Refik), Bosnalt Samuraylar (Les samouraïs bosniaques), Ankara : Vadi, 1997.

156 - Bora (Tanll), Yeni Dünya düzeni'nin av savași : Bosna-Hersek (La guerre prédatrice du nouvel ordre international : la Bosnie-Herzégovine), Istanbul : Birikim, 1994, $330 \mathrm{p}$.

157 - Gürbüz (Bahadır), Batidan Dogu'ya uzanan çizgide Balkanlar ve Türkler : (1996-1999 Makedonya ve Bosna-Hersek) (Les Turcs et les Balkans entre l'Occident à l'Orient :1996-1999, Macédoine et Bosnie-Herzégovine), Konya : Çizgi, 2002, 269 p.

158 - Tekin (Arslan), Balkan Volkan (Le volcan balkanique), Istanbul : Ötüken, 1993, $351 \mathrm{p}$. Récit d'un voyage effectué en 1992 (Bulgarie, Grèce, Macédoine, Kosovo) par un éditorialiste du quotidien Ortadogu. 
159 - Balbay (Mustafa), Balkanlar (Les Balkans), Istanbul : Çağdaș, zème édition, 1998, 159 p. Récit de voyage (Bulgarie, Macédoine, Albanie, Serbie, Bosnie) par un éditorialiste du quotidien Cumhuriyet.

16o - Bākiler (Yavuz Bülent), Üsküp'ten Kosova'ya (De Skopje au Kosovo), Ankara : Türk

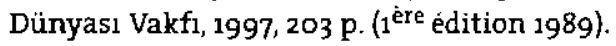

Récit de voyage entrecoupé d'anecdotes, de poèmes et de témoignages.

161 - Özfatura (Necati), Hedefteki ülke, Kosova (Kosovo, le pays ciblé), Istanbul : İzci, 1998, $221 \mathrm{p}$.

Recueil d'articles d'un éditorialiste du quotidien Türkiye.

162 - Karatay (Osman), Balkanlarm Gülen Çehresi (Le visage souriant des Balkans), Ankara : Kurali Mat., 1999, 169 p.

Recueil de chroniques, couvre les années 1997-1998.

163 - Fürüzan, Balkan yolcusu: gezi-röportaj (Voyage dans les Balkans : reportages), Istanbul : Yapı Kredi, 1996, 193 p.

164 - Elveriş (İdil), New Orleans'tan Kosovo'ya. Bir Türk kzzmm anulan (De la Nouvelle Orléans au Kosovo. Journal d'une jeune femme turque), Istanbul : Aykır1, 2002, 195 p.

Journal d'une jeune femme turque qui a travaillé à l'UNMIK. Couvre environ un an de juillet 2000 à juin 2001.

165 - Tokay (Gül), Makedonya Sorunu. Jön Türk Ihtilälinin Kökenleri (1903-1908) (La question macédonienne. Les origines de la révolution jeune-turque - 1903-1908), Istanbul : Afa, 1996, $212 \mathrm{p}$.

Publication d'une thèse ; sources : archives ottomanes (Başbakanllk notamment) et autrichiennes (Haus-Hof- und Staats-Archiv, Kriegs Archiv).

166 - Börekçi (Mehmet Çetin), Osmanl Imparatorluğu'nda Sirp meselesi (La question serbe dans l'Empire ottoman), Istanbul : Kutup Yildız1, 2001, 199 p.

167 - Bozbora (Nuray), Osmanl yönetiminde Arnavutluk ve Arnavut ulusçuluğunun gelişimi (L'Albanie sous régime ottoman et le développement du nationalisme albanais), Istanbul : Boyut, 1997,300 p.

168 - Çelik (Bilgin), Ittihatçlar ve Arnavutlar : II. Meşrutiyet döneminde Arnavut ulusçuluğu ve Arnavutluk sorunu (Les Albanais et le Comité Union et Progrès : le nationalisme albanais et la question albanaise à l'époque de la deuxième Constitution), Istanbul : Büke Kitaplan, 2004, $536 \mathrm{p}$.

169 - Inanç (Üstün), Makedonya Gamzesi : Osmanlmın çıkamadŭı Jön Türk Tüneli (Le clin d'œil macédonien : le tunnel jeune-turc dont les Ottomans ne peuvent sortir). Istanbul : Okul, 2004, 242 p.

170 - Bulgaristan devrimci gençlik haraketi tarihi (Histoire du mouvement de la jeunesse révolutionnaire en Bulgarie), Istanbul : Evrensel, 1999. 
171 - Birdoğan (Nejat), Anadolu ve Balkanlarda Alevi yerleșmesi : ocaklar-dedeler-soyağaçlan (Le peuplement alévi en Anatolie et dans les Balkans : les foyers-les dedes-les généalogies), Istanbul : Mozaik, 1995, $292 \mathrm{p}$.

172 - İki Dünya Șavașı arasmda Avrupa ve Balkanlar. İdeolojiler ve uluslarası politika (L'Europe et les Balkans durant l'entre-deux guerre. Idéologie et politique internationale), Istanbul : Albay, 1994, $229 \mathrm{p}$.

Actes d'un colloque organisé en janvier 1993. Les nationalismes en Europe et dans les Balkans durant l'entre-deux guerre, les Balkans dans les enjeux internationaux, les relations turco-allemandes.

173 - Hezarfen (Ahmet), Rumeli ve Anadolu Âyan ve eșkiyası- Osmanlı arșiv belgeleri (Les brigands et notables provinciaux anatoliens et balkaniques - documents d'archives ottomans), Istanbul : Kaynak, 2004, 374 p.

Présentation des documents d'archives en ottoman accompagnés de leur traduction en turc.

174 - Engin (Vahdettin), Rumeli demiryollarl (Les chemins de fer balkaniques), Istanbul : Eren, 1993, $303 \mathrm{p}$.

Histoire de la construction des chemins de fer dans les Balkans, avec cartes et illustrations,

175 - Ağanoğlu (Yıldırım), Osmanlidan Cumhuriyete Balkanlar'mn Makûs Talihi : göç (La destinée malheureuse des Balkans de l'époque ottomane à la république : les migrations), Istanbul : Kum Saat1, 2001, 397 p. (index)

176 - Çalislar (İzzettin), Görgülü (İsmet), eds., On ylllı savașm günlüğü : Balkan, Birinci Dünya ve İstiklal Savașlan (Journal d'une décennie de guerres : les guerres balkaniques, mondiale (Première) et d'indépendance), Istanbul : Yapı Kredi, 1997, 416 p.

177 - Öztürk (Ali), Rumeli'den Bursa'ya. Bulgaristan'dan Türkiye'ye. Hayatım ve Haturatım (Des Balkans à Bursa, de la Bulgarie à la Turquie. Ma vie et mes mémoires), introduction par Mustafa Öcal, Bursa : Düșünce, 2004, 261 p.

Récit d'une vie, mémoires et correspondance d'Ali Öztürk (1923-), Turc de Bulgarie qui a émigré en Turquie en 1950, membre de l'Institut islamique de Bursa.

178 - Kâni İrtem (Süleyman), Osmanlı Devleti'nin Makedonya Meselesi (Le problème macédonien de l'État ottoman), présentés par Osman Selim Kocahanoğlu, Istanbul : Temel, 1999, $304 \mathrm{p}$.

Les œuvres de Süleyman Kâni İrtem, ancien kaymakam en Macédoine (fin XIX ème - début $\mathrm{XX}^{\text {ème)}}$ ) et membre du Comité Union et Progrès.

179 - Ardıcı (Mehmet), Yücelciler 1947 : Makedonya'da müslüman direniși : Mehmet Ardıcínm anıları (Les partisans de "Yücel " en 1947 - la résistance musulmane en Macédoine, les mémoires de Mehmet Ardıc1), Istanbul : İnsan Yayınlan, 1991, 296 p.

180 - Cemal (Yübași), Arnavutluk'tan Sakarya'ya komitacllı: Yüzbașı Cemal'in anıları (Des komitadjis de l'Albanie jusqu'à Sakarya : mémoires du capitaine Cemal), préparé par Kudret Emiroğlu, Ankara : Kebikeç, 1996, 63 p.

Histoire militaire - mémoires d'un officier - guerre 1912-1913. 
181 - Muhtar Pașa (Mahmud), Balkan Savașı Üçüncü Kolordu'nun ve İkinci Doğu Ordusu'nun muharebeleri, (La guerre balkanique. Les combats du Troisième Corps d'armée et de la Deuxième Armée orientale), Istanbul : Güncel, 2003, $175 \mathrm{p}$.

Le journal d'un officier de l'armée ottomane sur le front, octobre-novembre 1912.

182 - Akseki (Ahmet Hamdi), Bulgaristan mektuplan (Lettres de Bulgarie), Istanbul : Rağbet, 2001, $119 \mathrm{p}$.

Correspondance de Ahmet Hamdi Akseki (1887-1951), écrivain et homme de religion.

183 - İsen (Mustafa), İsen (Reyhan), Balkanlarda Türk Çocuk Șiiri Antolojisi (Anthologie de la poésie turque pour enfant dans les Balkans), Istanbul : Grafikler Meslek Kuruluşu, 2001, 441 p.

184 - İsen (Mustafa), Ötelerden bir ses : divan edebiyatı ve Balkanlarda Türk edebiyatı üzerìne makaleler (Une voix d'ailleurs : articles sur la littérature de Divan et la littérature turque dans les Balkans), Ankara : Akçağ, 1997. 581 p.

185 - Cumalı (Necati), Makedonya 1900 : öyküler (La Macédoine dans les années 1900 : Histoires), Istanbul : Çağdaş, 1995, $191 \mathrm{p}$.

186 - Akın (Nur), Balkanlarda Osmanl dönemi konutlar (Les maisons dans les Balkans à l'époque ottomane), Istanbul : Literatür, 2001, $242 \mathrm{p}$.

187 - Kahraman (İsmail), Bulgaristan'da Osmanll Medeniyeti (La civilisation ottomane en Bulgarie), Gebze/Kocaeli : Anadolu Basin ve Yayincllik, 1999, 145 p.

Présentation historique de villes bulgares et des monuments ottomans qui s'y trouvent. Composé sous forme de fiches par villes ou personnages.

188 - Mexcan (Hasan), Sevinç uzak bir düștü : bir Yugoslav Kosova Türk șairinin savaş günlüğü (Le bonheur était un rêve lointain : journal de guerre d'un poète turc kosovar), Ankara : Orijin, 2000, 72 p.

189 - Mercan (Hasan), Elele : Kosovalt șairler antolojisi (Main dans la main : anthologie de la poésie kosovare), Ankara : Damar, 1999, 112 P.

190 - Kaya (Fahri), ed., Boşnak edebiyatı antolojisi (Anthologie de la littérature bochniaque), Istanbul : Yapi Kredi, 1997, $323 \mathrm{p}$.

191 - Gümüş (İsmail), Boşnak Türküsü : öyküler (Les chants populaires bochniaques : histoires), Ankara : Ardıç, 1994, 102 P.

192 - L̇eti (Metin), Balkanlar'da Tasarvuf (Le soufisme dans les Balkans), Istanbul : Gelenek, 2004, 351 p.

193 - Balkanlarda Türk ünlüleri : ansiklopedik bilgiler (Les Turcs célèbres dans les Balkans : informations encyclopédiques), Istanbul : Bizim Yurt, 1999, 295 p.

194 - Çavușoğu (Halim), Balkanlar'da Pomak Türkleri : Tarih ve sosyal kültürel yapl (Les Turcs pomaks dans les Balkans : histoire et structures socio-culturelles), Ankara : Köksav Vakfi, 1993. $221 \mathrm{p}$. 
195 - İsen (Mustafa), Balkanlar'da Türk kültür varlı̆ı (Présence culturelle turque dans les Balkans), Ankara : Turk Kadınlanı Kültür Derneği, 1993, 48 p.

196 - Nesin (Aziz), Bulgaristan'da Türkler, Türkiye'de Kürtler (Les Turcs en Bulgarie, les Kurdes en Turquie), Istanbul : Adam, 1992, 215 p.

197 - Kahramanyol (Mustafa), Makedonya'daki Türk ve müslüman toplumlarmm vatanmdan ve hayatindan manzaralar (Vues sur la vie et sur la patrie dans les sociétés musulmane et turque en Macédoine), Ankara : Senoğlu, 2003, 99 p.

198 - Edreniç (Mirza), Pınar (Birsen), Begoviç (Șükrü ), eds., Boșnakça-Türkçe TürkçeBoșnakça (turc-bosniaque / bochniaque-turc - dictionnaire), Istanbul : Fono Açıöğretim Kurumu, 1994, 412 p.

199 - Hengirmen (Mehmet), Türkçe öğreniyorüz : Türkçe-Boșnakça anahtar kitap (Apprenons le turc : manuel turc-bochniaque), Ankara : Engin, 1993, 3 volumes.

200 - Millas (Herkül), Türk-Yunan ilișkilerine bir önsöz (Une introduction aux relations gréco-turques), Istanbul : Kavram, 1995, $184 \mathrm{p}$.

201 - Millas (Herkül), Yunan ulusunun doğușu (La naissance de la nation grecque), Istanbul : Iletișim, 1994, $408 \mathrm{p}$.

202 - Millas (Herkül), Türk Romanı ve 'öteki' / ulusal kimlikte Yunan imajı (Les romans turcs et l'Autre / l'image du Grec dans l'identité nationale), Istanbul : Sabancı Üniversitesi, 2000, 382 p. Quelques 450 œuvres littéraires turques couvrant la fin de la période ottomane et toute la période républicaine sont passées en revue.

203 - Gürel (Ș̈̈krü), Tarihsel Boyut içinde Türk Yunan İlișkileri (1821-1993) (Les relations grécoturques dans leurs dimensions historiques), Ankara : Ümit, 1993, 181 p.

204 - Demirbaș (Bülent), Batı Trakya Sorunu (La question de la Thrace occidentale), Istanbul : Arba, 1996, $196 \mathrm{p}$.

205 - Türgay (C̣in), Yunanistan'daki Müslüman Türk Azınlığı din ve vicdan özgürlüğü (Liberté de conscience et de religion chez la minorité musulmane turque de Grèce), Ankara : Seçkin, $2003,154 \mathrm{p}$.

206 - Berber (Engin), ed., Izmir 1920 : Yunanistan ișgali altmdaki bir kentin öyküsü (Izmir 1920 : Histoire d'une ville sous occupation grecque), Izmir : Akademi Kitabevi, 1998, 104 p.

207 - Tosun (Ramazan), Türk-Yunan ilişkileri ve nüfus mübadelesi - 1821-1930 (Les relations turco-grecques et l'échange de population), Ankara : Berikan, 2002, 179 p.

208 - Hatipoğlu (Murat), Yakm tarihte Türkiye ve Yunanistan (1923-1954) (La Grèce et la Turquie dans l'histoire récente -1923-1954), Ankara : Siyasal Kitabevi, 1997, 343 p.

209 - Gökaçtı (Mehmet Ali), Geographika : yeniden keșfedilen Yunanistan (Géographica : La Grèce redécouverte), Istanbul : Illetișim, 2001, 616 p. 
210 - Sönmezoğu (Faruk), Türkiye-Yunanistan ilişkileri ve büyük güçler : Kıbrss, Ege ve diğer sorunlar (Les relations turco-grecques et les Grandes puissances : Chypre, la mer Égée et autres questions), Istanbul : Der, 2000,403 p.

211 - Sofuogu (Adnan), Fener Rum Patrikhanesi ve siyaset faaliyetleri (Le patriarcat 'rum' du Phanar et ses activités politiques), Istanbul : Turan, 1996, 259 p.

212 - Celik (Mehmet), Türkiye'nin Fener Patrikhanesi meselesi : ABD'nin Yeni Dünya Düzeni Projesi'nde Ortodoks aleminin yeniden yaplandirlması II. Vatikan Projesi : Fener Patrikhanesi'ne verilecek ökümeniklik statüsünün Türkiye için doğuracağı tehlikeler (La question du patriarcat du Phanar en Turquie : La restructuration du monde orthodoxe dans le projet de Nouvel Ordre international des États-Unis ou le projet Vatican II. Les dangers pour la Turquie de l'octroi d'un statut œcuménique au patriarcat), Izmir : Akademi Kitabevi, 1998, $106 \mathrm{p}$.

213 - Çelik (Mehmet), Fener Patrikhanesi'nin ökümeniklik iddiasının tarihi seyri (325-1453) (Les évolutions historiques des revendications d'œecuménisme du patriarcat du Phanar), Izmir : Akademi Kitabevi, 2000, 285 P.

214 - Atalay (Bülent), Fener Rum Ortodoks Patrikhanesi'nin siyasi faaliyetleri 1908-1923 (Les activités politiques du patriarcat orthodoxe " num " du Phanar), Istanbul : Tarih ve Tabiat Vakfi, 2001, $350 \mathrm{p}$.

215 - Günay (Tuncer), Misyonerler ve Fener Rum Patrikhanesi : Haçllarm ajan-provokatör kollar (Les missionnaires et le patriarcat orthodoxe " rum " : le bras provocateur-agitateur des croisades), Ankara : Berikan, 2002, $35^{2}$ p.

216 - Macar (Rlçin), Istanbul Rum Patrikhanesi (Le patriarcat orthodoxe ('grec') d'Istanbul), Istanbul : İletișim, 2003, $357 \mathrm{p}$.

Étude du patriarcat oecuménique d'Istanbul à partir des archives turques (Başbakanlık). 